\title{
Green Human Resource Management and Green Supply Chain Management: linking two emerging agendas
}

\author{
Charbel José Chiappetta Jabbour*, Ana Beatriz Lopes de Sousa Jabbour ${ }^{1}$ \\ UNESP - Univ Estadual Paulista (Sao Paulo State Univ), Av. Eng. Ed. Carrijo Coube, 14-01, DEP-FE, Zip Code 17033360 Bauru, SP, Brazil
}

\section{A R T I C L E I N F O}

\section{Article history:}

Received 17 February 2014

Received in revised form

23 July 2014

Accepted 3 January 2015

Available online 28 January 2015

\section{Keywords:}

Green Supply Chain Management (GSCM)

Green Human Resource Management

(GHRM)

Supply chain management (SCM)

Human resource management (HRM)

Sustainable operations management

Sustainable supply chain management

(SSCM)

Organizational sustainability

\begin{abstract}
A B S T R A C T
Green Human Resource Management (GHRM) and Green Supply Chain Management (GSCM) are popular subjects in the areas of human resource management (HRM) and operations management (OM), respectively. Although scholars in each of these areas are advancing the roles of GSCM and GHRM in building more sustainable organizations, there has been a significant delay in the integration of these two contemporary subjects, based on a greater gap in the integration of HRM and supply chain management (SCM). Thus, the aims of this study are to propose a synergistic and integrative framework for the GHRM-GSCM relationship and to propose a research agenda for this integration. After reaching these goals, this article emphasizes the implications of GHRM-GSCM integration for scholars, managers, and practitioners in the areas of organizational sustainability and truly sustainable supply chains.
\end{abstract}

๑) 2015 Elsevier Ltd. All rights reserved.

\section{Introduction}

The subject of environmental sustainability and greening organizations is increasingly present in managerial agendas (GonzálezBenito and González-Benito, 2006), causing a green revolution in traditional, established disciplines (Marcus and Fremeth, 2009), such as human resources (Jackson et al., 2014; Renwick et al., 2013; Jabbour et al., 2010) and operations management (Govindan et al., 2014a; Gunasekaran and Ngai, 2012; Gunasekaran and Spalanzani, 2012; Sarkis, 2001). In the field of human resources, the theme of "Green Human Resource Management" (GHRM) has emerged (Jackson et al., 2011; Renwick et al., 2013, 2008), establishing itself as a new line of research (Jackson and Seo, 2010; Ones and Dilchert, 2012; Jackson et al., 2014; Jabbour, 2013). In the field of operations management, sustainability also has gained attention (Govindan et al., 2014a; Gunasekaran and Spalanzani, 2012) and is becoming a new competitive dimension (Thürer et al., 2013), and topics such

\footnotetext{
* Corresponding author. Tel./fax: +55 1431036122.

E-mail addresses: charbel@feb.unesp.br (C.J.C. Jabbour), abjabbour@feb.unesp.br (A.B.L. de Sousa Jabbour).

${ }^{1}$ Tel./fax: +55 1431036122 .
}

as "Green Supply Chain Management" (GSCM) are becoming increasingly important, mobilizing the scientific community (Sarkis, 2012; Govindan and Cheng, 2011; Seuring and Müller, 2008). Thus, GHRM and GSCM are impacting the agendas of scholars and practitioners in HRM and operations management, respectively.

However, these two popular subjects are emerging and gaining force in a disconnected manner. Furthermore, to advance organizational sustainability, the innovative fusion of organizational theories (Sarkis et al., 2011) and the elaboration of synergistic frameworks are needed (Seuring and Müller, 2008) to elaborate on "how" organizations can become more sustainable (Pagell and Shevchenko, 2014). GHRM and GSCM must be analyzed in a connected manner because organizations, and consequently operations management, are people intensive (i.e., they involve senior management, managers, employees, and suppliers) (Croson et al., 2013; Bendoly et al., 2006; Boudreau et al., 2003; Santos, 2000). When multiple organizations are combined, coordinated, and structured in supply chains, more people are involved, human relations are more complex, and behavioral issues are therefore highlighted (Santos, 2000). As affirmed by Gowen and Tallon (2003), HRM can indeed have a positive influence on SCM. Lengnick-Hall et al. (2013) consider the integration of HRM and 
SCM to be a neglected area of research, and in the same manner, Ellinger and Ellinger (2014) affirm that HRM can contribute to the success of SCM practices. Based on these broader arguments on the positive - and scarce - relationship between HRM and SCM in the literature, it is also possible to presume that GHRM can be positive for GSCM, but the literature on this topic is equally scarce.

Thus, if the operations and supply chain tend to become greener (Sarkis, 2012) and to move toward more advanced GSCM, GHRM will also be relevant because behavioral aspects are important for environmental management (Graves et al., 2013; Wagner, 2013; Teixeira et al., 2012; Unikrishnam and Hedge, 2007). Consequently, GHRM-GSCM integration has grown in importance.

However, the current state of the art developments in organizational sustainability lack of a framework and a research agenda that integrate these two emerging, profitable fields of knowledge and that create synergy in the GHRM-GSCM relationship. In contrast, this type of multidisciplinary integration is necessary to advance in the field of sustainable supply chains (Pagell and Shevchenko, 2014). For example, searches conducted using the ISI Web of Science and Scopus databases prior to July 2014 revealed that, to date, there are no published articles joining "Green Human Resource Management" and "Green Supply Chain Management" in a proper manner. There are works emphasizing the relevance of the integration between HRM and SCM (Ellinger and Ellinger, 2014; Lengnick-Hall et al., 2013; Gowen and Tallon, 2003; McAfee et al., 2002) more broadly, without considering "green" issues. Thus, each of the GHRM and GSCM fields of knowledge appears to be evolving in isolation, although they need each other. Building a bridge between GSCM and GHRM is important because GHRM is essential for the effective greening of organizations (Aragón-Correa et al., 2013; Cantor et al., 2012; Brío et al., 2008, 2007; Bohdanowicz, 2006), and GSCM is part of the concept of SSCM that is so relevant when organizations are pursuing sustainability (Beske and Seuring, 2014).

GHRM-GSCM integration is based on the following assumptions:

- Truly sustainable supply chains will require more multidisciplinary research, such as the integration of GHRM and GSCM proposed in this work (Pagell and Shevchenko, 2014);

- Human resources are key to excellent operations management (Croson et al., 2013; Bendoly et al., 2006; Boudreau et al., 2003), including aspects of SCM (Santos, 2000);

- HRM can have a positive influence on reducing the barriers to a successful SCM implementation (Gowen III and Tallon, 2003);

- If human resources are critical to SCM (Santos, 2000), they also tend to be critical to GSCM (Muduli et al., 2013), reducing the barriers associated with the adoption of GSCM practices;

- In the context of greener organizations, HRM tends to be transformed into GHRM (Jackson et al., 2011; Renwick et al., 2013); and

- GSCM, as an advanced, proactive approach to environmental management in organizations (Sarkis, 2012), tends to mobilize behavioral (Graves et al., 2013) and human (Muduli et al., 2013) aspects, making it intensive to GHRM.

Thus, the aims of this study are to: (a) present the main assumptions of GHRM; (b) present the main assumptions of GSCM; (c) argue in favor of integrating these two emerging fields of knowledge; (d) demonstrate how these two fields of knowledge are related, based on a synergistic and integrative framework; and (e) propose an agenda for future studies of GHRM-GSCM.

To meet these goals, Section 2 presents the methodological procedures used for the GHRM-GSCM integration, Section 3 presents the conceptual evolution of GHRM and its practices, Section 4 provides a plan for conceptual recovery of GSCM and its practices, Section 5 presents the synergistic framework for the GHRM-GSCM integration and an initial research agenda for the area, and Section 6 , presents this study's final considerations and implications for scholars, managers, practitioners, and students in the areas of GHRM and GSCM.

\section{Research procedures}

This study is conceptual, and its main goal is to integrate two emerging subjects in organizational sustainability: GHRM and GSCM. Studies that integrate concepts/theories are important in establishing connections between areas that do not generally converse with each other (Sarkis, 2012; Boudreau et al., 2003; Daily and Huang, 2001). GHRM and GSCM are popular subjects in the areas of human resources (Jackson et al., 2011; Renwick et al., 2013; Jackson et al., 2014) and operations management (Gunasekaran and Ngain, 2012; Govindan et al., 2014a), respectively, but until now, an adequate conceptual link has not been established between these emerging research agendas. This type of integration is also being pursued in a broader scope, connecting HRM and SCM (LengnickHall et al., 2013).

Until now (July 2014), searches conducted using the Scopus and ISI Web of Science (ISI-WoS), which were searched because they are considered the two main scientific databases used by scholars worldwide (Bartol et al., 2014), found no studies clearly proposing the integration of GHRM and GSCM (based on searches for "Green Human Resource Management" and "Green Supply Chain Management", considering titles and abstracts with no restrictions or limitations to the field of knowledge). There are studies that have indirect implications for the link between these two areas (Muduli et al., 2013), but there has not yet been any proposal for clear integration, as we propose here.

Methodologically, this study is based on the following main assumptions:

- HRM is critical to the success of SCM (Gowen III and Tallon, 2003), and HRM concepts and practices can support the implementation of supply chain practices (Ellinger and Ellinger, 2014);

- New and multidisciplinary points of view are needed when pursuing more sustainable supply chains (Pagell and Shevchenko, 2014);

- The GHRM field of study (definition and main practices) is based on the main works on the subject (e.g., Jackson et al., 2011; Renwick et al., 2013; Daily and Huang, 2001; Jabbour and Santos, 2008; Jabbour et al., 2010; Govindarajulu and Daily, 2004; Wagner, 2013);

- The GSCM field of study (definition and main practices) is based on the main practices of the topic (e.g., Diabat and Govindan, 2011; Govindan and Cheng, 2011; Sarkis et al., 2011; Srivastava, 2007; Vachon and Klassen, 2008, 2006; Zhu et al., 2008); and

- Guidelines exist for theory building in management (Wacker, 1998).

The methodological steps of this study are shown in Fig. 1.

The conceptual/theoretical approach of this study is justified by: the absence of similar studies clearly proposing the integration of these two popular subjects; the integration of these two emerging topics, which has motivated several calls for papers in prestigious journals (Govindan et al., 2014a; Linton et al., 2007; Ones and Dilchert, 2012; Renwick et al., 2012; Jackson et al., 2011); and the literature's findings on environmental sustainability, indicating that frameworks and conceptual studies are important for 


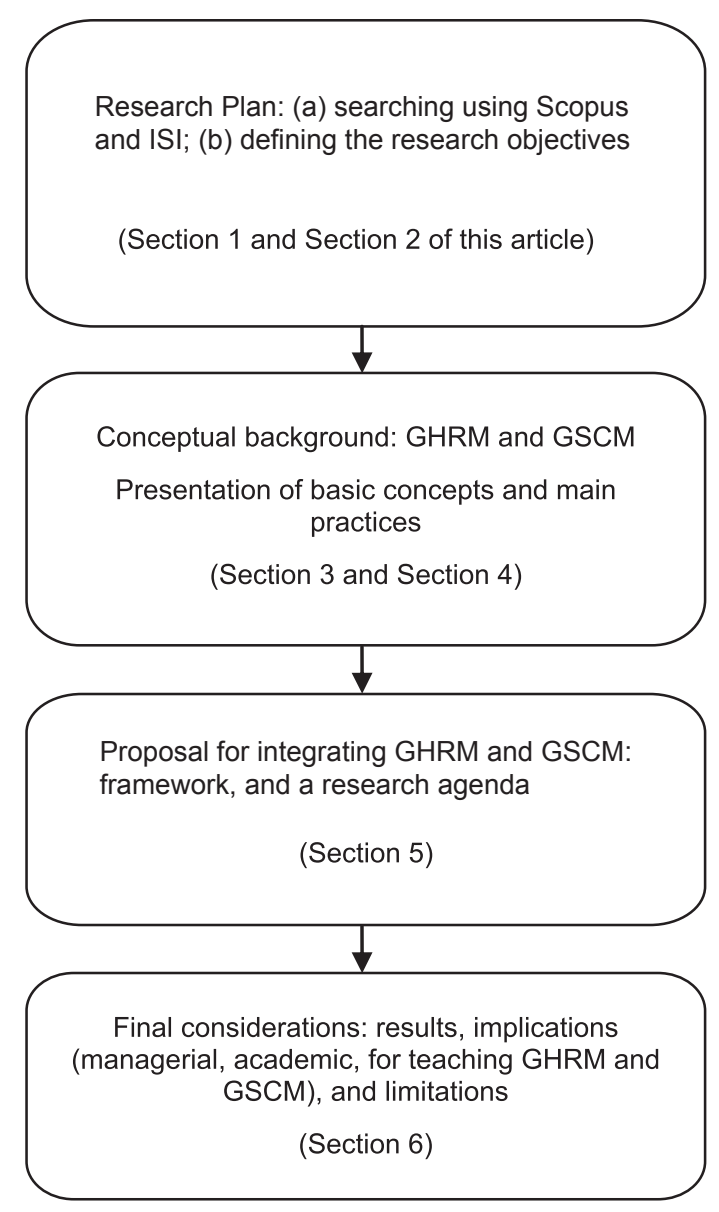

Fig. 1. Step-by-step description of this study.

advancing the topic and have been well-received by the academic community (Rheman and Shrivastava, 2013; Seuring and Müller, 2008; Ramus and Killmer, 2007; Angell and Klassen, 1999).

\section{Green Human Resource Management (GHRM)}

In the 1990s, studies on greening in organizations intensified (Wehrmeyer, 1996; Hale, 1995; Biehler-Baudisch, 1994). The primary explanation for this intensification is the expansion of environmental management systems and the launch of ISO14001, the most widely implemented environmental management system in the world (Jabbour and Santos, 2008; Chan, 2011). With increasing numbers of studies on organizational greening (Marcus and Fremeth, 2009), it became clear that organizations needed the support of human resource practices, such as training, performance evaluation, and rewards, to implement greening (Daily and Huang, 2001; Govindarajulu and Daily, 2004). The most important work during that time was related to human resources, and environmental management system. It was introduced by Wehrmeyer (1996) in the book Greening People. The need for HRM support for green issues was reinforced by works discussing more broadly the positive effects of human resources to firms' performance (Schuler and Jackson, 2014; Pauwe and Boselie, 2005; Guest, 1997).

Since that time, a series of studies have appeared on the subject, emphasizing the following:

- Human resource practices are critical for the implementation and maintenance of environmental management syst ems (Jabbour and Santos, 2008; Jabbour et al., 2008; Daily et al., 2007; Daily and Huang, 2001; Kitazawa and Sarkis, 2000);

- Human aspects are fundamental to the adoption of more advanced environmental practices (Boks, 2006; Brío et al., 2007, 2008; Sarkis et al., 2010; Graves et al., 2013);

- The development of products with lower environmental impact requires the support of human resources (Govindarajulu and Daily, 2004; Jabbour et al., 2008); and

- Environmental training stands out as one of the primary methods through which human resources support environmental management (Daily et al., 2012; Jabbour, 2013; Brío et al., 2008, 2007).

Until 2008, the integration of human resources and environmental management remained nameless. It was a study by Renwick et al. (2008) that named this emerging area and began to incorporate it more systematically into the research agenda of HRM, thus encouraging human resources scholars to include an environmental focus in their studies (Jackson et al., 2014, 2011). The term "Green Human Resource Management" (GHRM) was then coined (Renwick et al., 2008; Jackson and Seo, 2010; Renwick et al., 2013).

In 2011, Jackson et al. (2011) organized the first Special Issue on GHRM, decisively merging the research areas of human resources and environmental/green management. Since then, studies on GHRM have become more common, encouraging new Special Issues on the subject (Renwick et al., 2012).

Looking at the recent past in the area of GHRM, some research results are particularly relevant. There is a consensus that GHRM is established through the alignment of the HRM practices, with the aims of organizational environmental management (Jackson and Seo, 2010). In this context, Daily and Huang (2001) state that each of the phases of an environmental management system (from environmental policy to analysis of the results) requires the specific support of a human resource practice, with emphasis on recruitment and selection, training, performance evaluation, and rewards for employees. These practices are also relevant not only for supporting environmental management systems but also for supporting the development of products and innovations with lower environmental impacts (Govindarajulu and Daily, 2004). Jabbour and Santos (2008) contributed to this debate, indicating that the appropriate support for environmental management from human resources should involve the strategic involvement of human resources in the decision-making process regarding the organization's environmental aspects. These conceptual studies, along with the studies of Wehrmeyer (1996), Renwick et al. (2008), Jackson et al. (2011), Renwick et al. (2013), and others, constitute the background in the area of GHRM.

There are studies that relate support from human resources to a more proactive and evolved environmental management, as employee motivation is key to proactive behavior related to the environment (Graves et al., 2013). In this sense, Brío et al. (2008) and Brio et al. (2007) found that HRM is critical for the adoption of more advanced practices in environmental management. Jabbour et al. (2010) state that HRM had a decisive role in the evolution of environmental management in organizations and that human resource practices, such as performance evaluation and rewards, are critical to achieving more proactive environmental management.

GHRM involves both traditional human resource practices (recruitment, selection, performance evaluation, training, and rewards) aligned with environmental goals and "strategic dimensions for HRM" (Jabbour et al., 2010) or "new forms of work organization" (Longoni et al., 2014), such as organizational culture (Gupta and Kumar, 2013), teamwork (Jabbour et al., 2013), and 
employee empowerment (Daily et al., 2012). These practices and strategic dimensions of GHRM are defined below.

Recruitment and selection aim to attract potential applicants and hire them as employees of a given organization (Jabbour and Santos, 2008). The selection process aims to choose the ideal candidate for a position (Jabbour et al., 2010). Although it is clear that the recruitment and selection of employees who are committed to the environment are important for greening organizations, studies show that these practices do not always incorporate environmental aspects (Jabbour and Santos, 2008).

Another GHRM practice that has received substantial attention from scholars is environmental training (Jabbour, 2013). Environmental training was the topic of the first studies connecting human resources and environmental management, which emerged in the 1990s (Marshal and Mayer, 1992; Venselaar, 1995; Hale, 1995; Madsen and Ulhoi, 2001). More recently, Sarkis et al. (2010) stated that environmental training is relevant to allow employees to adopt more advanced environmental management practices. Daily et al. (2012) analyzed the influences of environmental empowerment and environmental training (independent variables) on employees' perceptions of environmental performance (dependent variable). Those authors found that environmental training tended to influence environmental performance more than environmental empowerment. Teixeira et al. (2012) presented case studies on the relationship between environmental training and environmental management based on Brazilian cases, suggesting that these two variables of contemporary organizational management have co-evolved.

In the context of GHRM, performance evaluation and rewards are related to including environmental issues in the performance evaluation processes of employees and teams and in the methods of rewarding employees for their dedication to environmental goals (Jabbour and Santos, 2008). Calia et al. (2009) state that adequate evaluation and rewards for employees based on the results of environmental projects (for example, reducing pollution) are critical to companies becoming more environmentally proactive, and the support of human resources is important for advancing environmental management (Ramus and Steger, 2000) and for generating eco-innovations (Ramus, 2002).

In addition to these traditional human resource practices, GHRM also acts through the creation, with support from HRM, of a greener organizational culture (Gupta and Kumar, 2013; Jabbour and Santos, 2008), the environmental empowerment of employees (Daily et al., 2012) and the encouragement to form environmental teams (Jabbour et al., 2013; Daily et al., 2012) as solutions to complex environmental challenges. Organizational culture is a traditional subject in organizational management and, when aligned with environmental management, refers to the values related to environmental sustainability that are shared by members of an organization (Harris and Crane, 2002). Environmental empowerment is important for ensuring that employees have the knowledge and autonomy to make decisions about complex environmental problems that may emerge and win-win opportunities that can arise with improvements in sustainability (Daily and Huang, 2001; Daily et al., 2012). Finally, environmental teams may involve employees from the same department/area, different departments/ areas, or different companies both to analyze complex problems in environmental management and to implement more advanced environmental practices (Jabbour et al., 2013).

One of the challenges for researchers in HRM who want to focus on GHRM is understanding the practices of environmental management because these practices have a direct relationship with operations management, involving the entire supply chain in the search for greater environmental sustainability. Therefore, the next section is dedicated to GSCM.

\section{Green Supply Chain Management (GSCM)}

The only way for organizations to address the search for sustainability seriously is by involving the entire supply chain (Vachon and Klassen, 2008). In the context of sustainable operations management (Grimm et al., 2014; Gunasekaran et al., 2014; Walker et al., 2014) and more sustainable supply chains in order to achieve economic, social, and green targets (Berke and Seuring, 2014; Pagell and Shevchenko, 2014; Linton et al., 2007), the concept of "Green Supply Chain Management" (GSCM) is relevant. GSCM, that is, the search for greater environmental efficiency in supply chains, is one of the most important subjects in the modern study of operations management (Kannan et al., 2014; Gunasekaran and Ngai, 2012; Gunasekaran and Spalanzani, 2012).

Two of the pioneering studies in the field of green supply chain management are Sarkis et al. (2011) and Sarkis (1995). At this early point in the history of GSCM, we can also cite Sarkis and Rasheed (1995), who emphasized the importance of integrating environmental issues in production and operations management into companies. Sarkis $(1998,2003)$ also contributed to the subject by proposing GSCM complexity and decision-making models to the adoption of environmentally conscious business practices. Comprehensive literature reviews on the subject confirmed the relevance of inserting green aspects into supply chain issues (Srivastava, 2007; Seuring and Müller, 2008), contributing further to the consolidation of this field of research.

GSCM, as a subsystem of a sustainable supply chain (Berke and Seuring, 2014; Seuring, 2013), can be defined as the integration of environmental issues into the inter-organizational practices of SCM, including reverse logistics (Sarkis et al., 2011). Hervani et al. (2005) agree with this definition of GSCM when emphasizing the adoption of green purchasing, green manufacturing, greener distribution of products, and reverse logistics. Additionally, Vachon and Klassen (2006) affirm that GSCM aims to improve environmental management through environmental collaboration or through the resolution of mutual problems that reduce the environmental risks in supply chains.

Zhu et al. (2008) empirically investigated constructs to study GSCM practices in manufacturing companies. Their results point to the importance of the following practices: internal environmental management, green purchasing, cooperation with consumers, ecodesign, and recovering investments. Reverse logistics has also been noted as a GSCM practice (Srivastava, 2007). Each of the GSCM practices is defined below:

- Internal environmental management-Internal environmental management is an important GSCM practice that requires the commitment and support of senior and mid-level managers (Green et al., 2012).

- Green purchasing-According to Min and Galle (2001), the practice of environmentally conscious purchasing seeks to reduce sources of waste and to promote recycling and the recovery of materials without affecting the performance of material requirements, in addition to considering the reduction or elimination of hazardous items (Eltayeb and Zailani, 2010). For this process to take place, according to Zsidisin and Siferd (2001), it is important to rethink the issues along with the criteria for acquiring and selecting materials and evaluating the development of suppliers.

- Cooperation with customers-This cooperation requires collaboration in designing cleaner production processes that can produce more environmentally sustainable products and that use green packaging (Zhu et al., 2008). Collaborative activities with customers include joint planning sessions related to the environment, activities to share knowledge about a product's 
ecodesign or the modification of processes, and waste reduction in the logistics process (Vachon and Klassen, 2006).

- Ecodesign-This term signifies the incorporation of environmental concerns into different stages of product development. According to Luttropp and Lagerstedt (2006), there are several rules for success in ecodesign, such as: (1) not using toxic substances; (2) minimizing energy and resource consumption in the production, transportation, and use stages; (3) trying to reduce product weight; (4) providing repairs and updates to products with dependent systems; (5) promoting long lives for products with significant environmental impacts; and (6) designing products so they are easily repairable, recyclable, and collapsible.

- Recovery of investments-Such recover signifies the capital gain for a company from the sale of excess materials, the sale of scrap and used materials, and the sale of excess capital goods from equipment replacement (Zhu et al., 2008).

- Reverse logistics-Reverse logistics is the process of planning, implementing, and controlling the efficient, low-cost flow of obsolete materials from the point of consumption to the point of origin, with the goal of recovering value or providing an appropriate destination (Sheriff et al., 2012). In general, the processes that make up reverse logistics are post-consumption product collection, along with inspection and identification of their most appropriate destinations, which can include disassembly for reuse of the parts, return to the company for remanufacture, or sending the materials to specialized recycling companies (Pokharel and Mutha, 2009).

These GSCM practices can be classified as more internal or more external. The internal GSCM practices are internal environmental management, ecodesign, and investment recovery; the external practices usually include green purchasing and cooperation with customers (Zhu et al., 2008). According to Green et al. (2012), companies tend to adopt internal GSCM first, followed by external GSCM. Similarly, Zhu et al. (2012) affirm that external GSCM can improve firms' performance after the adoption of internal GSCM.

By searching in major databases (e.g., Scopus and ISI Web of Science), it is possible to see that frequently addressed topics in studies of GSCM include the following: (a) the impact of GSCM on organizational performance (environmental, operational, or economic; e.g., Mitra; Datta, 2013; Lee et al., 2012; Green et al., 2012); (b) selection criteria for suppliers in the context of GSCM (e.g., Kannan et al., 2014, 2013; Hsu et al., 2013); and (c) the analysis of pressures and barriers to adopting GSCM (e.g., Govindan et al., 2014b; Mathiyazhagan et al., 2014; Xu et al., 2013). This latter topic underscores the organizational and human aspects of the primary barriers, including the lack of training, lack of involvement from senior management in adopting GSCM, and lack of crossfunctional communication and cooperation (Govindan et al., 2014b).

As already noted, the adoption of GSCM practices and their extension across the supply chain require the involvement and support of human resources. The previous literature has already emphasized the relevance of HRM to successful SCM (Lengnick-Hall et al., 2013), but the link between GHRM and GSCM remains missing. Some possibilities for this integration are discussed in Section 5 .

\section{GHRM-GSCM: an integrated perspective}

HRM plays a key role in organizational performance (Jackson et al., 2014) and in the adoption of organizational practices (Schuler and Jackson, 2014). This context is not different from successful SCM implementation: HRM is also necessary, but the relationship between HRM and SCM remains a neglected area of research (Lengnick-Hall et al., 2013), and the insertion of "green issues" makes discussion of this relationship increasingly scarce and neglected, justifying the integration of GSCM and GHRM proposed in this work.

The broader relevance of HRM to SCM can be found in some arguments from the literature:

- SCM has been considered the most popular operations strategy for improving organizational competitiveness in the twentyfirst century, requesting support from human factors (Gunasekaran et al., 2008);

- HR professionals have skills (training, teamwork, and others) that are useful for disseminating a deeper and broader understanding of the SCM concept within organizations (Ellinger and Ellinger, 2014); corporate culture and HRM policies have important impacts on the success of that organization's SCM strategy (McAfee et al., 2012);

- HRM is also relevant not only to SCM adoption but also to other contemporary operations management concepts and practices, for example, lean manufacturing (Martínez-Jurado et al., 2013);

- Human resource factors mitigate the adverse effects of implementation barriers on the success of SCM practices (Gowen III and Tallon, 2003);

- Human resource factors (teamwork, training, and rewards) can be adopted to reinforce the collaboration among members in a supply chain (Vanichchinchai, 2012); and

- Human factors, such as flexible job descriptions, team building, teamwork training, and the use of performance metrics to determine rewards, are significantly related to satisfaction with supply chain performance (Menon, 2012).

Even recognizing that the area of $\mathrm{OM}$ is human resource intensive (Boudreau et al., 2003; Santos, 2000) and that, therefore, in the GSCM context, there must be support from GHRM, there are no current studies dedicated to an in-depth analysis of this relationship or that propose an integrative framework and an initial research agenda. The study by Muduli et al. (2013) shows some results related to the indirect support of organizational factors for GSCM, and Ho et al. (2012) shows that HR factors are relevant to the adoption of reverse logistics. Cantor et al. (2012) demonstrate the importance of employee perceptions in advancing employee-level involvement in environmental behaviors.

Thus, it is believed that the "green" theme, along with the greening of organizations (Marcus and Fremeth, 2009), is the cornerstone of the integration of GSCM and GHRM. The "green" in question is a unique opportunity to facilitate integration and contribute to organizations' transitions to a more sustainable society. The multidisciplinary approach linking these emerging fields of research is an opportunity to contemplate truly sustainable supply chains (Pagell and Shevchenko, 2014).

Therefore, to strengthen the GHRM-GSCM relationship, a synergistic and integrative GHRM-GSCM framework is proposed, as depicted in Fig. 2. In the title of the framework, the term "GHRM" precedes "GSCM" because it is believed that human factors are the basis for greening of the supply chain. The relevance of HRM to the success of SCM has been discussed in the literature (Ellinger and Ellinger, 2014; Lengnick-Hall et al., 2013) and should be used as an important argument to support the GRHM-GSCM relationship.

In this framework, it is possible to see the entire complexity of this integration. GHRM is analyzed by reference to human resource practices (recruitment, selection, training, performance evaluation, and rewards) and human factors, which constitute the basis of any organizational change in favor of sustainability, such as organizational culture, teamwork, and empowerment. The findings of Paillé 


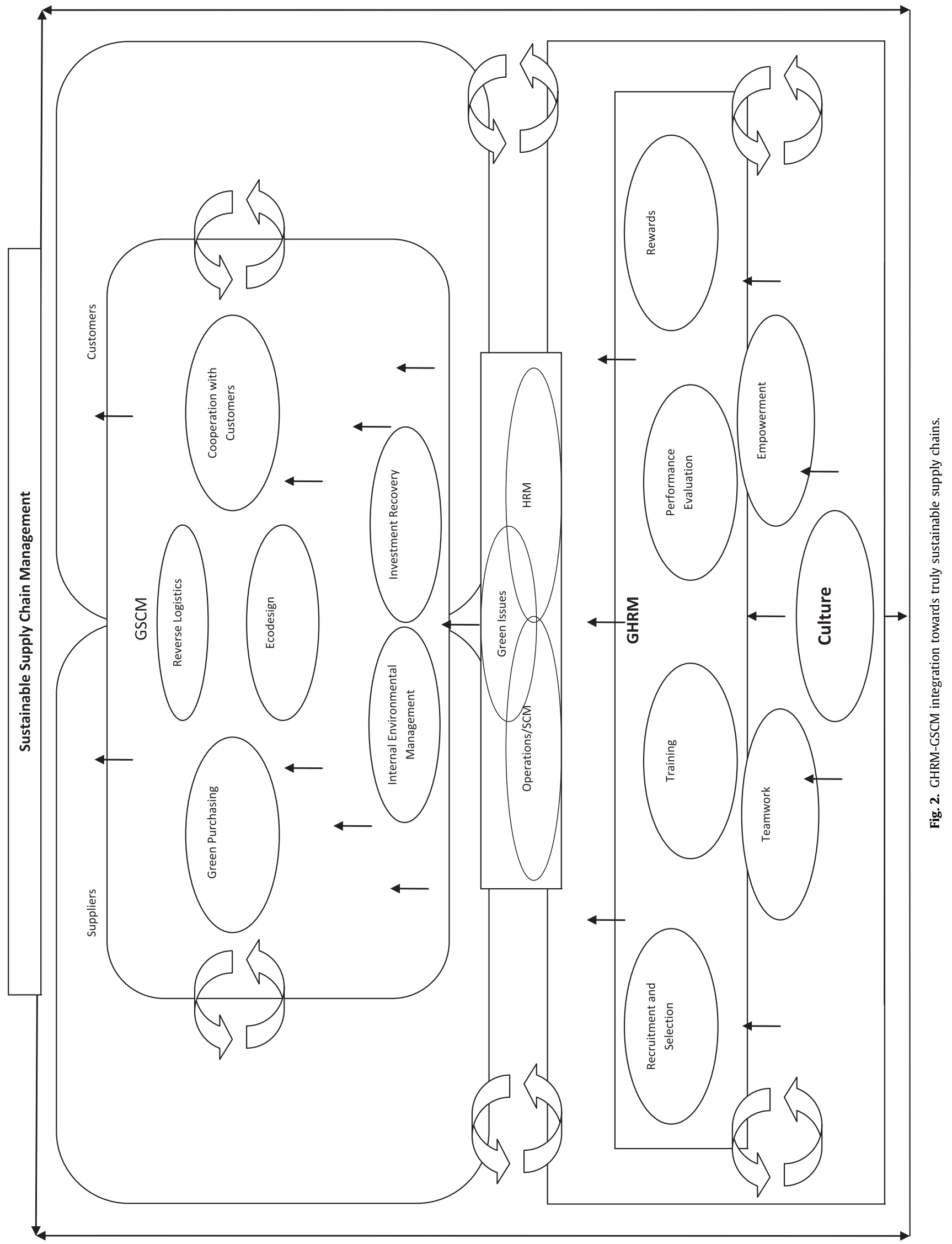


et al. (2014) reinforce the relevance of human resources to environmental performance, primarily in terms of alignment of HRM system/practices to firms' green values and principles.

Additionally, it is relevant to consider the human factors that are the bases of change management regarding the greening of firms (Daily and Huang, 2001). In this framework, the GSCM practices suggested by Zhu et al. (2008) are also present. All of these concepts should be understood in the multidisciplinary context of sustainable organizations and SSCM (Beske and Seuring, 2014; Pagell and Shevchenko, 2014).

The GHRM-GSCM framework should be understood through a bottom-up perspective and reading. From this standpoint, organizational culture is the most important and most relevant human factor in the greening of organizations (Harris and Crane, 2002), based on top management support (Kannan et al., 2014), values, and principles for supporting environmental management in companies (Jabbour et al., 2010). Once a green culture is established, teamwork and empowerment will be necessary to discuss and make decisions regarding complex problems and new perspectives on GSCM. The relevance of green teamwork and empowerment has been emphasized by Daily et al. (2012), Jackson et al. (2011) and others. These more intangible human resources factors will form the basis of GHRM-GSCM integration because they are also relevant to the broader integration between HRM and SCM (Lengnick-Hall et al., 2013; Gowen and Tallon, 2003).

Green culture, teamwork, and empowerment will be connected to more traditional HRM practices (recruitment, selection, training, performance evaluation, and rewards), which constitute the mainstream of GHRM (Renwick et al., 2013). These more traditional GHRM practices are more tangible and may guarantee that green issues will be considered in organizational routines.

In the upper part of the framework, it is necessary to explain that GSCM practices have a sequential implementation, with internal practices first and external practices second (Green et al., 2012). Internal environmental management should be the first GSCM adopted. This practice will occur with the increasing strength of green organizational culture, green teams, and empowerment. Internal environmental management will prepare the territory for the adoption of other GSCM practices, and because of this preparation, management will require support from GRHM practices to incentivize the greening of employees' behavior (Paillé et al., 2014). At this time, employees will be encouraged to consider waste management, pollution prevention, eco-efficiency, and the GSCM practice called investment recovery. The adoption of GSCM ecodesign will require stronger connections between the firm and other supply chain players to produce greener products, following the human resource support discussed by Govindarajulu and Daily (2004), with special attention paid to green teams (Jabbour et al., 2013) and to green jobs that will require technical green training because of the complexity of ecodesign activities (Sarkis et al., 2010). Green purchasing and collaboration with customers will require special green training to make workshops and meetings available on topics of GSCM issues (Arantes et al., 2014). Reverse logistics, because of their complexity, will require employees with a strong external orientation, requiring support from GHRM (Ho et al., 2012; de Sousa Jabbour et al., 2013).

The support of GHRM tends to become more intense when a company's limits are extrapolated (from internal environmental management and investment recovery), and GSCM practices that involve collaboration with customers and suppliers begin to be adopted, based on ecodesign and reverse logistics initiatives. It is believed that all of the practices of GSCM and GHRM are interconnected and tend to be related synergistically, contributing to the higher part of the framework: SSCM (Beske and Seuring, 2014).
As a result, the contribution of this study is that it suggests a framework for GSCM-GHRM synergistic integration as an analytical frame for the reality of companies that seek to improve their sustainability performance. This framework facilitates understanding of the complexity of the successful adoption of GSCM practices, based on the support of GHRM. The framework also shows that more intangible GHRM factors, such as culture, teamwork, and empowerment, form the basis of GSCM. Internal GSCM practices and investment recovery will be the first step towards more advanced and external GSCM and will require more intense support from HRM to achieve a more sustainable supply chain.

A special challenge in this process is sharing the same practices of GHRM and GSCM and the same level of GHRM-GSCM integration and synergy along the entire supply chain. This comprehensiveness will require a special effort by the focal company/main firm in the supply chain.

The main recommendation for future studies is to explore the adherence and validity of the proposed framework through qualitative (multiple case studies and interviews) and/or quantitative (empirical data) studies and simulations, as suggested by Pagell and Shevchenko (2014). Furthermore, guided by the challenges of GHRM-GSCM integration presented in the literature, Table 1 provides more specific opportunities for advancing research.

A key question regarding GHRM-GSCM integration is whether human resources will support GSCM by reducing the barriers faced by managers when implementing these GSCM practices. Thus, as in previous studies of HRM-SCM integration (Gowen III and Tallon, 2003), the reduction of SCM implementation barriers/challenges is the primary measurement of the success of HRM support. Thus, Table 1 shows the main HRM barriers affecting GSCM implementation. Eliminating these barriers will reinforce the relationship between GHRM-GSCM synergy and more sustainable supply chains.

GSCM can also contribute to firms' performance and then contribute to the capacity of firms to invest in human resources development and corporate social responsibility. Thus, the relationship between GHRM and GSCM can contribute to more sustainable firms and supply chains and to sustainable development.

\section{Final considerations}

The aim of this study is to link two subjects that are considered hot subjects in their areas of origin (operations and human resources) but that have not yet been completely integrated: GSCM and GHRM. The broader literature on HRM-SCM has already stated that the interrelationship between these fields of knowledge has been neglected (Lengnick-Hall et al., 2013). This gap is deeper when inserting "green" as a point of view regarding innovative ways of thinking that truly contribute to sustainable supply chains (Pagell and Shevchenko, 2014). To meet this goal, this paper presents the GSCM-GHRM synergistic integrative framework and the elements of a future research agenda in the area. These proposals have the following implications:

- Academic implications-adding a relationship that is littleexplored in the literature by integrating GSCM and GHRM through a framework that discusses the "how" of more sustainable supply chains (Pagell and Shevchenko, 2014);

- Managerial implications-presenting a proposal for professionals to integrate GSCM and GHRM, thus helping improve companies' sustainable performance. It is necessary to analyze how the GHRM-GSCM relationship could contribute to truly sustainable organizations, including social and economic aspects and synergy; 
Table 1

GRHM-GSCM: reduction of human barriers when implementing GSCM and proposed questions for future research.

\begin{tabular}{|c|c|}
\hline GSCM practices & Barriers/challenges to GSCM implementation that GHRM can reduc \\
\hline $\begin{array}{l}\text { Internal Environmental } \\
\text { Management }\end{array}$ & $\begin{array}{l}\text { The barriers to implementation include human and organizational } \\
\text { issues, such as: (a) lack of knowledge and skills (Studer et al., } 2006 \\
\text { Collins et al., 2007; Chan, 2011); (b) lack of support from senior } \\
\text { management (Studer et al., 2006; Kehbila et al., 2009; Chan, 2011) } \\
\text { (c)lack of awareness (Studer et al., 2006; Kehbila et al., 2009); and } \\
\text { (d) lack of green attitude and culture (Hillary, 2004). }\end{array}$ \\
\hline
\end{tabular}

Green purchasing

Cooperation with Customers

Ecodesign

Investment Recovery

Reverse Logistics
According to Preuss (2005), some reasons for the not so high involvement of the supply chain in environmental initiatives are: (a) economic benefits of environmental initiatives; and (b) the need to include improvements in environmental performance. There is a need for increased interaction among purchasing, environmental, and other functions (Nawrocka et al., 2009). According to Yen and Yen (2012), commitment from senior management is a major issue when adopting green purchasing initiatives.

According to Eltayeb et al. (2011), there are three main activities for cooperation with customer: (a) education of the customer-using, for example, environmental awareness seminars; (b) support of the customer-the creation, for example, of environmental support teams in the development of environmental programs; and (c) joint ventures-for example, having the company work with the customer to establish common teams and long-term programs to develop green innovations and solutions, such as clean technologies, and green product projects.

Among the main obstacles to ecodesign, according to Boks (2006), are: (a) a gap between the creators and implementers of ecodesign projects; (b) organizational complexity; (c) lack of cooperation among departments/areas; and (d) lack of environmental goals and visions in projects.

Support from senior management and the creation of mechanisms to create company gains from the sale of excess materials, the sale of scraps and used materials, and the sale of excess capital goods from equipment replacement (Zhu et al., 2008)

Managerial/human aspects tend to be barriers to implementing reverse logistics (such as lack of commitment), as is the lack of human resources (such as skilled personnel and training in reverse logistics) (Abdulrahman et al., 2014). lack of awareness by supply chain managers regarding the
Suggestions for a research agenda providing insights into how GHRM can support GSCM by reducing barriers

- How can each human resources practice help strengthen internal environmental management?

- Do companies with greater adoption of GHRM also adopt GSCM?

- What is the impact on firm performance of adopting GSCM and GHRM?

- Which GHRM practices can support the adoption of internal environmental management?

- How can one overcome the main barriers to GHRM-GSCM integration?

- What are the main corporate motivations for GSCM-GHRM integration?

- How can one offer appropriate incentives and build organizational culture for adopting GSCM?

- What are the best GHRM practices to support the adoption of green purchasing?

- What are the main human challenges to adopting green purchasing?

- What are the main benefits for employees and organizational performance provided by the adoption of green purchasing?

- How do green teams support green purchasing?

- How has empowerment supported green purchasing?

- How can GHRM contribute to broader collaboration between departments/areas and between companies along a supply chain?

- How can senior management encourage the adoption of green purchasing through GHRM?

- How can HRM contribute so that cooperation with a customer occurs in the context of GSCM?

- How can GHRM help customers to become more environmentally aware?

- What are the characteristics of environmental teams that are focused on customer collaboration?

- What is the role of GHRM in creating long-term partnerships with environmental customers?

- Are companies with more intense GHRM also the companies that cooperate with environmental customers?

- How has GHRM supported the adoption of ecodesign?

- How can GHRM work with experts in ecodesign to ensure employee involvement?

- How can one build empowered environmental teams so that the different departments/areas of a company work collaboratively?

- How is it possible to encourage eco-innovations through GHRM?

- How can GHRM encourage employees to reduce waste and pursue cleaner production?

- How is it possible to train employees in recycling or investment recovery?

- How can environmental teams be formed to ensure that investment recovery is viable?

- What are the impacts on GHRM and on the performance of GSCM, of adopting investment recovery?

- How it is possible to provide technical knowledge of reverse logistics to all of the departments/areas involved?

- How is it possible to offer environmental training to the tiers in a reverse chain?

- How is it possible to encourage, through GHRM, the adoption of reusable and recyclable materials in the production of new products?

- What is the appropriate organizational culture for organizations that are intensively involved in reverse logistics?

- How can environmental teams be empowered to adopt reverse logistics?

- How can senior management support the adoption of reverse logistics?
- Implications for practitioners-enabling organizational consultants and policy makers from cleaner industries to begin to incorporate human and organizational aspects into the implementing of GSCM, as well as showing "how" the proposed framework can be applied; and
- Implications for teaching-GSCM and GHRM are central topics in courses/subjects on organizational sustainability. This article could help scholars and students to understand better the debate on these topics' limits and the possibility of integrating them in sustainable supply chains (Beske and Seuring, 2014); 
these fields of research will require innovative ways of thinking to be developed fully (Pagell and Shevchenko, 2014).

\section{Acknowledgements}

Research reported in this work was partially supported by CNPq - Brazilian Council for Scientific and Technological Development (Grant \#304225/2013-4; Grant \#303484/2013-6; Grant \# 232060/2013-4).

\section{References}

Abdulrahman, M.D., Gunasekaran, A., Subramanian, N., 2014. Critical barriers in implementing reverse logistics in the Chinese manufacturing sectors. Int. J. Prod. Econ. 147, 460-471.

Angell, L.C., Klassen, R.D., 1999. Integrating environmental issues into the mainstream: an agenda for research in operations management. J. Oper. Manag. 17 (5), 575-598.

Aragón-Correa, J.A., Martín-Tapia, I., Hurtado-Torres, N.E., 2013. Proactive environmental strategies and employee inclusion: the positive effects of information sharing and promoting collaboration and the influence of uncertainty. Organ. Environ.

Arantes, A.F., Jabbour, A.B.L.D.S., Jabbour, C.J.C., 2014. Adoption of Green Supply Chain Management practices: mechanisms of induction and the role of focal companies. Production.

Bartol, T., Budimir, G., Dekleva-Smrekar, D., Pusnik, M., Juznic, P., 2014. Assessment of research fields in Scopus and Web of Science in the view of national research evaluation in Slovenia. Scientometrics 98 (2), 1491-1504.

Bendoly, E., Frohlich, M.T., Dixon, J.R., 2006. Editorial - incorporating behavioral theory in OM empirical models replication in operations management research. J. Oper. Manag. 24 (6), 731-733.

Beske, P., Seuring, S., 2014. Putting sustainability into supply chain management. Supply Chain Manag. Int. J. 19 (3), 8-8.

Biehler-Baudisch, H., 1994. Environmental training in Germany. J. Eur. Ind. Train. 18 (3), 10-16.

Bohdanowicz, P., 2006. Environmental awareness and initiatives in the Swedish and Polish hotel industries - survey results. Int. J. Hosp. Manag. 25, 662-682.

Boks, C., 2006. The soft side of ecodesign. J. Clean. Prod. 14 (15), 1346-1356.

Boudreau, J., Hopp, W., McClain, J.O., Thomas, L.J., 2003. On the interface between operations and human resources management. Manuf. Serv. Oper. Manag. 5 (3), 179-202.

Brío, J.A., Fernández, E., Junquera, B., 2007. Management and employee involvement in achieving an environmental action-based competitive advantage: an empirical study. Int. J. Hum. Resour. Manag. 18 (4), 491-522.

Brío, J.A., Junquera, B., Ordiz, M., 2008. Human resources in advanced environmental approaches - a case analysis. Int. J. Prod. Res. 46 (21), 6029-6053.

Calia, R.C., Guerrini, F.M., de Castro, M., 2009. The impact of Six Sigma in the performance of a Pollution Prevention program. J. Clean. Prod. 17 (15), 1303-1310.

Cantor, D.E., Morrow, P.C., Montabon, F., 2012. Engagement in environmental behaviors among supply chain management employees: an organizational support theoretical perspective. J. Supply Chain Manag. 48 (3), 33-51.

Chan, E.S.W., 2011. Implementing environmental management systems in small and medium sized hotels: obstacles. J. Hosp. Tour. Res. 35 (3), 3-23.

Collins, E., Lawrence, S., Pavlovich, K., Ryan, C., 2007. Business networks and the uptake of sustainability practices: the case of New Zealand. J. Clean. Prod. 15, 729-740.

Croson, R., Schultz, K., Siemsen, E., Yeo, M.L., 2013. Behavioral operations: the state of the field. J. Oper. Manag. 31 (1-2), 1-5.

Daily, B.F., Huang, S., 2001. Achieving sustainability through attention to human resource factors in environmental management. Int. J. Oper. Prod. Manag. 21 (12), 1539-1552.

Daily, B., Bishop, J.W., Steiner, R., 2007. The mediating role of EMS teamwork as it pertains to HR factors and perceived environmental performance. J. Appl. Bus. Res. 23 (1), 95-110.

Daily, B.F., Bishop, J.W., Massoud, J.A., 2012. The role of training and empowerment in environmental performance: a study of the Mexican maquiladora industry. Int. J. Oper. Prod. Manag. 32 (5), 631-647.

de Sousa Jabbour, A.B.L., de Souza Azevedo, F., Arantes, A.F., Jabbour, C.J.C., 2013. Green supply chain management in local and multinational high-tech companies located in Brazil. Int. J. Adv. Manuf. Technol. 68 (1-4), 807-815.

Diabat, A., Govindan, K., 2011. An analysis of the drivers affecting the implementation of green supply chain management. Resour. Conserv. Recycl. 2011 (55), 659-667.

Ellinger, A.E., Ellinger, A.D., 2014. Leveraging human resource development expertise to improve supply chain managers' skills and competencies. Eur. J. Train. Dev. 38 (1/2), 118-135.

Eltayeb, T.K., Zailani, S., 2010. Investigation on the drivers of green purchasing towards environmental sustainability in the Malaysian manufacturing sector. Int. J. Procure. Manag. 3 (3), 316-337.
Eltayeb, T.K., Zailani, S., Ramayah, T., 2011. Green supply chain initiatives among certified companies in Malaysia and environmental sustainability: investigating the outcomes. Resour. conserv. Recycl. 55 (5), 495-506.

González-Benito, J., González-Benito, O., 2006. A review of determinant factors of environmental proactivity. Bus. Strategy Environ. 15, 87-102.

Govindan, K., Cheng, T.C., 2011. Environmental supply chain management. Resour. Conserv. Recycl. 55 (6), 557-558.

Govindan, K., Kaliyan, M., Kannan, D., Haq, A.N., 2014b. Barriers analysis for green supply chain management implementation in Indian industries using analytic hierarchy process. Int. J. Prod. Econ. 147, 555-568.

Govindan, K., Sarkis, J., Jabbour, C.J.C., Zhu, Q., Geng, Y., 2014a. Eco-efficiency based green supply chain management: current status and opportunities. Eur. J. Oper. Res. 233 (2), 293-298.

Govindarajulu, N., Daily, B.F., 2004. Motivating employees for environmental improvement. Ind. Manag. Data Syst. 104 (4), 364-372.

Gowen III, C.R., Tallon, W.J., 2003. Enhancing supply chain practices through human resource management. J. Manag. Dev. 22 (1), 32-44.

Graves, L.M., Sarkis, J., Zhu, Q., 2013. How transformational leadership and employee motivation combine to predict employee proenvironmental behaviors in China. J. Environ. Psychol. 35, 81-91.

Green Jr., K.W., Zelbst, P.J., Meacham, J., Bhadauria, V.S., 2012. Green supply chain management practices: impact on performance. Supply Chain Manag. Int. J. 17 (3), 290-305.

Grimm, J.H., Hofstetter, J.S., Sarkis, J., 2014. Critical factors for sub-supplier management: a sustainable food supply chains perspective. Int. J. Prod. Econ. 152, 159-173.

Guest, D.E., 1997. Human resource management and performance: a review and research agenda. Int. J. Hum. Resour. Manag. 8 (3), 263-276.

Gunasekaran, A., Spalanzani, A., 2012. Sustainable development of manufacturing and services: investigations for research and applications. Int. J. Prod. Econ.

Gunasekaran, A., Lai, K.H., Edwin Cheng, T.C., 2008. Responsive supply chain: a competitive strategy in a networked economy. Omega 36 (4), 549-564.

Gunasekaran, A., Ngai, E.W.T., 2012. The future of operations management: an outlook and analysis. Int. J. Prod. Econ. 135, 687-701.

Gunasekaran, A., Irani, Z., Papadopoulos, T., 2014. Modelling and analysis of sustainable operations management: certain investigations for research and applications. J. Oper. Res. Soc. 65 (6), 806-823.

Gupta, S., Kumar, V., 2013. Sustainability as corporate culture of a brand for superior performance. J. World Bus. 48 (3), 311-320.

Hale, M., 1995. Training for environmental technologies and environmental management. J. Clean. Prod. $3(1-2), 19-23$.

Harris, L.C., Crane, A., 2002. The greening of organizational culture: management views on the depth, degree and diffusion of change. J. Organ. Change Manag. 15 (3), 214-234.

Hervani, A.A., Helms, M.M., Sarkis, J., 2005. Performance measurement for green supply chain management. Benchmarking: Int. J. 12 (4), 330-353.

Hillary, R., 2004. Environmental management systems and the smaller enterprise. J. Clean. Prod. 12, 561-569.

Ho, G.T.S., Choy, K.L., Lam, C.H.Y., Wong, D.W., 2012. Factors influencing implementation of reverse logistics: a survey among Hong Kong businesses. Meas. Bus. Excell. 16 (3), 29-46.

Hsu, C.W., Kuo, T.C., Chen, S.H., Hu, A.H., 2013. Using DEMATEL to develop a carbon management model of supplier selection in green supply chain management. J. Clean. Prod. 56, 164-172.

Jabbour, C.J.C., Santos, F.C.A., Nagano, M.S., 2010. Contributions of HRM throughout the stages of environmental management: methodological triangulation applied to companies in Brazil. Int. J. Hum. Resour. Manag. 21, 1049-1089.

Jabbour, C.J.C., Santos, F.C.A., 2008. Relationships between human resource dimensions and environmental management in companies: proposal of a model. J. Clean. Prod. 16, 51-58.

Jabbour, C.J.C., 2013. Environmental training in organisations: from a literature review to a framework for future research. Resour. Conserv. Recycl. 74 (1), $144-155$.

Jabbour, C.J.C., Almada Santos, F.C., Fonseca, S.A., Nagano, M.S., 2013. Green teams: understanding their roles in the environmental management of companies located in Brazil. J. Clean. Prod. 46, 58-66.

Jackson, S., Renwick, D., Jabbour, C.J.C., Muller-Camen, M., 2011. State-of-the-Art and future directions for green human resource management. Z. Personalforsch. Ger. J. Res. Hum. Resour. Manag. 25, 99-116.

Jackson, S.E., Schuler, R.S., Jiang, K., 2014. An aspirational framework for strategic human resource management. Acad. Manag. Ann. 1-89 (just-accepted).

Jackson, S.E., Seo, J., 2010. The greening of strategic HRM scholarship. Organ. Manag. J. 7 (4), 278-290.

Kannan, D., Jabbour, A.B.L.D.S., Jabbour, C.J.C., 2014. Selecting green suppliers based on GSCM practices: using fuzzy TOPSIS applied to a Brazilian electronics company. Eur. J. Oper. Res. 233 (2), 432-447.

Kannan, D., Khodaverdi, R., Olfat, L., Jafarian, A., Diabat, A., 2013. Integrated fuzzy multi criteria decision making method and multi-objective programming approach for supplier selection and order allocation in a green supply chain. J. Clean. Prod. 47, 355-367.

Kehbila, A.G., Ertel, J., Brent, A.C., 2009. Strategic corporate environmental management within the South African automotive industry: motivations, benefits, hurdles. Corp. Soc. Responsib. Environ. Manag. 16, 310-323.

Kitazawa, S., Sarkis, J., 2000. The relationship between ISO 14001 and continuous source reduction programs. Int. J. Oper. Prod. Manag. 20 (2), 225-248. 
Lee, S.M., Kim, S.T., Choi, D., 2012. Green supply chain management and organizational performance. Ind. Manag. Data Syst. 112 (8), 1148-1180.

Lengnick-Hall, M.L., Lengnick-Hall, C.A., Rigsbee, C.M., 2013. Strategic human resource management and supply chain orientation. Hum. Resour. Manag. Rev. 23 (4), 366-377.

Linton, J.D., Klassen, R., Jayaraman, V., 2007. Sustainable supply chains: an introduction. J. Oper. Manag. 25 (6), 1075-1082.

Longoni, A., Golini, R., Cagliano, R., 2014. The role of New Forms of Work Organization in developing sustainability strategies in operations. Int. J. Prod. Econ. $147,147-160$.

Luttropp, C., Lagerstedt, J., 2006. EcoDesign and the Ten Golden Rules: generic advice for merging environmental aspects into product development. J. Clean. Prod. 14 (15), 1396-1408.

Madsen, H., Ulhoi, J.P., 2001. Greening of human resources: environmental awareness and training interests within the workforce. Ind. Manag. Data Syst. 101 (2), 57-63.

Marcus, A., Fremeth, R., 2009. Green management matters regardless. Acad. Manag. Perspect. 23 (3), 17-26.

Marshall, M.E., Mayer, D.W., 1992. Environmental training: it's good business. Bus. Horiz. 2, 54-57.

Martínez-Jurado, P.J., Moyano-Fuentes, J., Jerez-Gómez, P., 2013. HR management during lean production adoption. Manag. Decis. 51 (4), 3-3.

Mathiyazhagan, K., Govindan, K., Noorul Haq, A., 2014. Pressure analysis for green supply chain management implementation in Indian industries using analytic hierarchy process. Int. J. Prod. Res. 52 (1), 188-202.

McAfee, R.B., Glassman, M., Honeycutt, E.D., 2002. The effects of culture and human resource management policies on supply chain management strategy. J. Bus. logist. 23 (1), 1-18.

Menon, S.T., 2012. Human resource practices, supply chain performance, and wellbeing. Int. J. Manpow. 33 (7), 769-785.

Min, H., Galle, W.P., 2001. Green purchasing practices of US firms. Int. J. Oper. Prod. Manag. 21 (9), 1222-1238.

Mitra, S., Datta, P.P., 2013. Adoption of green supply chain management practices and their impact on performance: an exploratory study of Indian manufacturing firms. Int. J. Prod. Res. 1-23 (ahead-of-print).

Muduli, K., Govindan, K., Barve, A., Kannan, D., Geng, Y., 2013. Role of behavioura factors in green supply chain management implementation in Indian mining industries. Resour. Conserv. Recycl. 76, 50-60.

Nawrocka, D., Brorson, T., Lindhqvist, T., 2009. ISO 14001 in environmental supply chain practices. J. Clean. Prod. 17 (16), 1435-1443.

Ones, D.S., Dilchert, S., 2012. Environmental sustainability at work: a call to action. Ind. Organ. Psychol. 5 (4), 444-466.

Paauwe, J., Boselie, P., 2005. HRM and performance: what next? Hum. Resour Manag. J. 15 (4), 68-83.

Pagell, M., Shevchenko, A., 2014. Why research in sustainable supply chain management should have no future. J. Supply Chain Manag. 50 (1), 44-55.

Paillé, P., Chen, Y., Boiral, O., Jin, J., 2014. The impact of human resource management on environmental performance: an employee-level study. J. Bus. Ethics 121 (3), 451-466.

Pokharel, S., Mutha, A., 2009. Perspectives in reverse logistics: a review. Resour Conserv, Recycl. 53 (4), 175-182.

Preuss, L., 2005. Rhetoric and reality of corporate greening: a view from the supply chain management function. Bus. Strategy Environ. 14 (2), 123-139.

Ramus, C.A., 2002. Encouraging innovative environmental actions: what companies and managers must do. J. World Bus. 37 (2), 151-164.

Ramus, C.A., Killmer, A.B., 2007. Corporate greening through prosocial extrarole behaviours-A conceptual framework for employee motivation. Bus. Strategy Environ, 16 (8), 554-570.

Ramus, C.A., Steger, U., 2000. The roles of supervisory support behaviors and environmental policy in employee "Ecoinitiatives" at leading-edge european companies. Acad. Manag. J. 43 (4), 605-626.

Rehman, M.A., Shrivastava, R.L., 2013. Green manufacturing (GM): past, present and future (a state of art review). World Rev. Sci. Technol. Sustain. Dev. 10 (1) 17-55.

Renwick, D.W., Redman, T., Maguire, S., 2013. Green human resource management: a review and research agenda. Int. J. Manag. Rev, 15 (1), 1-14.

Renwick, D., Redman, T., Maguire, S., 2008. Green HRM: a Review, Process Model, and Research Agenda. University of Sheffield Management School Discussion Paper.

Renwick, D., Jabbour, C.J.C., Muller-Camen, M., Redman, T., Wilkinson, A., 2012. Introduction to the Green (environmental) human resource management special issue. Int. J. Hum. Resour. Manag. 23, 3498-3499.

Santos, F.C., 2000. Integration of human resource management and competitive priorities of manufacturing strategy. Int. J. Oper. Prod. Manag. 20 (5), 610-628.
Sarkis, J., Gonzalez-Torre, P., Adenso-Diaz, B., 2010. Stakeholder pressure and the adoption of environmental practices: the mediating effect of training. J. Oper. Manag. 28 (2), 163-176.

Sarkis, J., 1995. Manufacturing strategy and environmental consciousness. Technovation 15 (2), 79-97.

Sarkis, J., 1998. Evaluating environmentally conscious business practices. Eur. J. Oper. Res. 107 (1), 159-174.

Sarkis, J., 2003. A strategic decision framework for green supply chain management. J. Clean. Prod. 11 (4), 397-409.

Sarkis, J., Rasheed, A., 1995. Greening the manufacturing function. Bus. Horiz. 38 (5), $17-27$

Sarkis, J., 2001. Manufacturing's role in corporate environmental sustainabilityConcerns for the new millennium. Int. J. Oper. Prod. Manag. 21 (5/6), 666-686.

Sarkis, J., 2012. A boundaries and flows perspective of green supply chain management. Supply Chain Manag. Int. J. 17 (2), 202-216.

Sarkis, J., Zhu, Q., Lai, K.H., 2011. An organizational theoretic review of green supply chain management literature. Int. J. Prod. Econ. 130 (1), 1-15.

Schuler, R., Jackson, S.E., 2014. Human resource management and organizational effectiveness: yesterday and today. J. Organ. Eff. People Perform. 1 (1), 35-55.

Seuring, S., 2013. A review of modeling approaches for sustainable supply chain management. Decis. Support Syst. 54 (4), 1513-1520.

Seuring, S., Müller, M., 2008. From a literature review to a conceptual framework for sustainable supply chain management. J. Clean. Prod. 16 (15), 1699-1710.

Sheriff, K.M.M., Gunasekaran, A., Nachiappan, S., 2012. Reverse logistics network design: a review on strategic perspective. Int. J. Logist. Syst. Manag. 12 (2), $171-194$.

Srivastava, S.K., 2007. Green supply-chain management: a state-of-the-art literature review. Int. J. Manag. Rev. 9 (1), 53-80.

Studer, S., Welford, R., Hills, P., 2006. Engaging Hong Kong business in environmental change: drivers ans barriers. Bus. Strategy Environ. 15, 416-431.

Teixeira, A.A., Jabbour, C.J.C., Jabbour, A.B.L.S., 2012. Relationship between green management and environmental training in companies located in Brazil: a theoretical framework and case studies. Int. J. Prod. Econ. 140 (1), 318-329.

Thürer, M., Godinho Filho, M., Stevenson, M., Fredendall, L.D., 2013. Competitive priorities of small manufacturers in Brazil. Ind. Manag. Data Syst. 113 (6), 856-874.

Unnikrishnan, S., Hedge, D.S., 2007. Environmental training and cleaner production in Indian industry - a micro-level study. Resour. Conserv. Recycl. 50, 427-441.

Vachon, S., Klassen, R.D., 2006. Extending green practices across the supply chain: the impact of upstream and downstream integration. Int. J. Oper. Prod. Manag. 26 (7), 795-821.

Vachon, S., Klassen, R.D., 2008. Environmental management and manufacturing performance: the role of collaboration in the supply chain. Int. J. Prod. Econ. 111 (2), 299-315.

Vanichchinchai, A., 2012. The relationship between employee involvement, partnership management and supply performance: findings from a developing country. Int. J. Prod. Perform. Manag. 61 (2), 157-172.

Venselaar, J., 1995. Environmental training: industrial needs. J. Clean. Prod. 3 (1-2).

Wacker, J.G., 1998. A definition of theory: research guidelines for different theorybuilding research methods in operations management. J. Oper. Manag. 16 (4), $361-385$.

Wagner, M., 2013. Green human resource benefits: do they matter as determinants of environmental management system implementation? J. Bus. Ethics 114, 443-456.

Walker, H., Klassen, R., Sarkis, J., Seuring, S., 2014. Sustainable operations management: recent trends and future directions. Int. J. Oper. Prod. Manag. 34 (5), $1-1$.

Wehrmeyer, W., 1996. Greening People, Human Resources and Environmental Management. Greenleaf, London.

Xu, L., Mathiyazhagan, K., Govindan, K., Noorul Haq, A., Ramachandran, N.V., Ashokkumar, A., 2013. Multiple comparative studies of green supply chain management: pressures analysis. Resour. Conserv. Recycl. 78, 26-35.

Yen, Y.X., Yen, S.Y., 2012. Top-management's role in adopting green purchasing standards in high-tech industrial firms. J. Bus. Res. 65 (7), 951-959.

Zhu, Q., Sarkis, J., Lai, K.H., 2008. Confirmation of a measurement model for green supply chain management practices implementation. Int. J. Prod. Econ. 111 (2), $261-273$.

Zhu, Q., Sarkis, J., Lai, K.H., 2012. Examining the effects of green supply chain management practices and their mediations on performance improvements. Int. J. Prod. Res. 50 (5), 1377-1394.

Zsidisin, G.A., Siferd, S.P., 2001. Environmental purchasing: a framework for theory development. Eur. J. Purch. Supply Manag. 7 (1), 61-73. 